\title{
The effects of predator odors on stress response and reproduction in Norway rats: A review
}

\author{
M.A. Klyuchnikova, P.V. Struchkov, I.G. Kvasha \\ A.N. Severtsov Institute of Ecology and Evolution, 119071, Leninski pr., 33, Moscow, Russia
}

Corresponding author E-mail: klyuchnikova@gmail.com

Received: 25.07.2020. Accepted: 25.08.2020

\begin{abstract}
Norway rat (Rattus norvegicus) is an invaluable laboratory model organism as well as one of the most common rodent pest species. The currently used rodenticides have several significant drawbacks: toxicity to humans and non-target species, environmental harm, the development of avoidance reactions and genetic resistance to the applied substances in rat populations. One of the proposed approaches for rodent pest control is based on natural ways, such as predation, which could be emulated by predator scents. In rodents, olfaction plays a key role in danger recognition, especially in detection of potential predator. Predator odors can activate the hypothalamic-pituitary-adrenal (HPA) axis via central nervous system and thus induce the release of stress hormones. A welldocumented suppression of reproduction under psychosocial stress appears to be associated with specific interactions of HPA axis and hypothalamus-pituitary-gonadal (HPG) axis. Hereby we review research on the influences of predator chemical cues on stress response and reproduction in Norway rats with a special focus on long lasting and chronic effects. We describe the effects of predator odors of fox (Vulpes vulpes), ferret (Mustela putorius) and domestic cat (Felis catus) in detail. Assessment of reproductive success in rats may be treated as a robust experimental model to evaluate ecologically relevant stress effects of predator odors. Application of this approach could promote development of environmentally friendly methods to control rat population density.
\end{abstract}

Keywords: Predator odor; Stress; Corticosterone; Reproduction; Norway rat

\section{Introduction}

Norway rat (Rattus norvegicus) is considered to be the first animal domesticated solely for the purpose of scientific research in the middle of the 19th century. Notably, one of the earliest published papers was related to endocrinology and described the effects of adrenalectomy in albino rats - surgical removal of adrenal glands, organs crucial in the response to stressors (Philipeaux, 1856; Lindsey \& Baker, 2006). After that, a bulk of physiological research of the second half of the 20th century utilized laboratory bred rats as model animals. Up to date rats remain a valuable commodity in scientific world. Their physiology provides researchers with an opportunity to model almost every pathological condition of human organs or systems. Laboratory rats are also widely used in behavioral and cognitive neuroscience research including the development of models for human emotional and mental illnesses, fields where they cannot be replaced with animals possessing lesser complexity of the behavioral response (Whishaw, 1999). At the same time, a wild Norway rat is one of the most common synanthropic pests. Rats transmit many infections harmful or deadly for humans such as plague, toxoplasmosis, tularaemia, leptospirosis, etc. (e.g. Strand \& Lundkvist, 2019). Harm to the local economy from the outgrowing rat population may include destruction of property and communication lines, partial consumption of stored food or its contamination. Increased probability of human-rat interactions in cities, where high building density and abundance of edible waste provide an ideal environment for rodents, calls for new methods of pest control (e.g. Voznessenskaya et al., 2004; Voznessenskaya \& Malanina, 2015). Current methods could be divided into two categories: direct elimination of rodents and measures to change living environment in order to limit propagation of rats. Chemicals used for rat extermination have a number of drawbacks, such as high toxicity for humans and non-target species as well as environmental pollution. Moreover, rats learn fast to avoid poisoned bait and develop genetic resistance upon application of anticoagulant rodenticides (e.g. Rylnikov et al., 1992; Buckle, 2013). Rodenticide survivors can also exhibit reproduction spur. Thus, long-term use of chemical agents acts as a driving force for selection of more resistant animals in rat population. For obvious reasons toxic substances cannot be applied in child facilities, hospitals and other establishments with high number of attendees. Considering described facts, a new generation of pest control methods is in great need. One of the possible approaches is based on natural ways of population control, such as predation, that could be emulated by introduction of predator scent marks, thus ensuring environmentally friendly and highly specific nature of the effect. In rodents olfaction plays a key role in danger recognition, especially in detection of potential predator. This method is in fact a special case of stress induced regulation of population density. Modern hypotheses explaining the mechanisms of dynamics of mammalian population are directly associated with an understanding of the role of stress. Species specificity of neuroendocrine mechanisms is of particular interest in this case (e.g. Christian \& Davies, 1964; Rogovin et al., 2003; Rogovin \& Moshkin, 2007).

\section{Literature Review} Adaptive response

In a widely accepted view, based on ideas of Selye (e.g. Selye, 1946), an integrative stress response system includes neuroanatomical and functional elements working simultaneously to sustain state of organism equilibrium - "homeostasis". "Stressors" in this paradigm 
are defined as factors threatening homeostasis, while any effort by the organism to counteract their affects is recognized as "adaptive response" (e.g. Johnson et al., 1992). The adaptive response then is a sum of physiological, biochemical and behavioral neutralizing reactions of organism. More recently, concepts of "allostasis", "allostatic load" and "allostatic overload" were introduced to distinguish between protective and damaging responses to stressors as well as to encompass developmental aspects (e.g. McEwen \& Wingfield, 2010). Individual response to stressors depends on a multitude of factors, both external and internal. External factors are the characteristics of the stressor itself, such as its quality (e.g. physical, emotional), intensity, and duration (e.g. acute, chronic). Internal factors are linked to individual characteristic of a subject, species or laboratory strain, such as genetic background, living environment, gender, age or previous encounters with the same stressor.

Activation of hypothalamic-pituitary-adrenal (HPA) axis is firmly associated with adaptive response. Upon exposure to stressor, a group of hypothalamic neurons of the paraventricular nucleus (PVN) secretes corticotropin-releasing factor (CRF), which in turn triggers release of adrenocorticotropic hormone (ACTH) in the anterior lobe of pituitary gland to the blood circulation. ACTH then stimulates synthesis and release of glucocorticoids from adrenal glands (Bale \& Vale, 2004). These steroid hormones are the end-product of activation the HPA axis. In rats and mice, the predominating glucocorticoid is corticosterone. Glucocorticoid content in blood circulation serves as good indicator of the current stage of adaptive response. Exposure to stressors causes elevation of corticosterone levels to some extent proportional to the intensity of disturbance. As there exists a negative feedback loop, high circulating corticosterone inhibits production of both CRF and ACTH (e.g. Keller-Wood \& Dallman, 1984; Sapolsky et al., 2000).

Although activation of the HPA axis reliably reflects acute stress, value of glucocorticoids as biomarkers of chronic stress is limited. One of the reasons for this is a methodological issue. Glucocorticoid content in blood serum and saliva reflects immediate changes in the HPA axis activity; so that, environmental disturbances, circadian rhythms and stress response to sampling techniques may interfere with the experimental outcome. Noninvasive monitoring of glucocorticoids in fecal and urine samples reflects a longer period of the HPA activity (24-48 h). A perspective technique of assessment of glucocorticoid deposition in animal hair, as biomarker of long-term HPA activity (1-2 months) so far has been applied only in a few experimental studies in Norway rats (e.g. Scorrano et al., 2015; Uarquin et al., 2016).

\section{HPA axis responses to predator odors in rats}

Predator odors can have a profound effect on the activation of the HPA axis and induce the release of stress hormones in rats as well as in other rodent species. Hormonal changes are expected to correlate with behavioral defensive responses (such as avoidance, changes in feeding behavior, etc.). However, clear dissociation between behavioral and neuroendocrine responses to predator odors was demonstrated in a number of studies (e.g. File et al., 1993; Perrot-Sinal et al., 1999). Odors from sympatric predators appear to be more effective, so that predator-prey co-evolutionary processes may be involved (See Apfelbach et al., 2005 for review).

\section{Reception of predator odors}

The olfactory system of rodents is thought to play a key role in detection of predators. In rats, as in most mammals and reptiles, there are two major olfactory subsystems, namely the main olfactory system (MOS) and the accessory olfactory system (AOS). Sensory neurons of the main olfactory epithelium mostly detect volatile odorants and project to the main olfactory bulbs, from which the signal is transmitted to the lateral amygdala, the primary olfactory cortex and to the brain areas involved in cognitive recognition of odors. Vomeronasal organ (VNO) that is a receptive organ of the AOS mostly perceives low-volatile substances and transmits signal to the accessory olfactory bulbs, the primary projection zone of which is the medial amygdala. In the light of current knowledge, both olfactory systems are able to respond to general and pheromonal odor cues (Voznessenskaya et al., 2010; Mucignat-Caretta et al., 2012 for review). Several minor chemosensory structures such as septal organ, trigeminal afferents and the Grueneberg ganglion also aid to olfactory recognition in rodents. Thus, upon reception predator odor cues are transmitted through the main olfactory and the accessory olfactory bulbs to the medial amygdala, particularly to its posteroventral part. Downstream the amygdala several interconnected hypothalamic nuclei (a medial hypothalamic circuit) are activated in response to predator odors. One of this nuclei, specifically, dorsomedial part of the ventromedial hypothalamus may be involved in the organization of endocrine stress-reactions (Gross \& Canteras, 2012).

\section{Fox predator odors}

One of the most studied predator-prey pairs is fox (Vulpes vulpes) and rat (Rattus norvegicus). Early laboratory observations of rats fear responses to fox odors (Vernet-Maury et al., 1968) were later confirmed by convincing field studies. Specifically, Fenn \& MacDonald (1995) encountered a shift of activity rhythms in wild rat population under risk of fox predation. Rat is generally a nocturnal species. However, being regularly visited by nocturnal foxes, the studied farm rat population exhibited diurnal foraging activity. A group of rats from the same population returned to the normal nocturnal activity after being placed in the protected enclosure (Fenn \& Macdonald, 1995). Vernet-Maury et al. (1984) tested stress-effects of a number of sulfur-containing compounds, which were originally isolated from fox feces, compared to concentrate of fox-dropping pentane extract. Of all the single molecule components 2,5-dihydro2,4,5-trimethylthiazoline (TMT) showed the greatest positive stress response as it was determined by the change of behavioral parameters in the open-field test and by the increase of blood corticosterone in Wistar rats (Vernet-Maury et al., 1984). Since then, a large body of research was accumulated on the effect of this single molecule as a model predator odor in rats (e.g. Rosen et al., 2015). Short TMT presentations resulted in the reliable increase of corticosterone and ACTH in blood plasma of rats (Day et al., 2004; Morrow et al., 2000). Under unescapable laboratory conditions fox odor naïve rats respond to TMT with distinguishable freezing reactions and do not habituate after repeated exposures to TMT (Wallace \& Rosen, 2000). Habituation, as a non-associative form of learning, reflects a decrease of an innate response to a stimulus after repeated or prolonged presentations of that stimulus. It is assumed that strong innate responses will habituate slowly, if at all. However, independent groups of researchers (Wallace \& Rosen, 2000; Dielenberg \& McGregor, 2001; McGregor et al., 2002; Blanchard et al., 2003) failed to observe fear conditioning with TMT odor at the behavioral level. Classical conditioning suggests that rats would easily associate a biologically potent unconditioned stimulus (such as predator odor) with previously conditioned neutral stimulus (e.g. novel chamber). Lack of fear conditioning may indicate that TMT is an insufficiently specific predator odor stimulus. Another study also failed to find elevated corticosterone responses in male Wistar rats reintroduced to the context in which TMT had been presented previously (Homiack et al., 2017). Mixed outcome from TMT studies may also be related to genetic background of test-subjects. Rosen et al. (2006) showed that Sprague-Dawley and Long-Evans rats displayed fear-related freezing reactions to TMT, whilst Wistar rats did not. In addition, Dias Soares et al. (2003) did not find any significant changes in blood plasma corticosterone content one week after exposure to TMT compared to water control (i.e. they observed lack of 
sensitization) in Sprague-Dawley rats. An important criticism is that TMT is a very volatile and acrid odor even at extremely low concentrations; so its effects may be attributed more to its noxious properties, rather than to predator signaling (Blanchard et al., 2003). Meanwhile, olfactory bulb removal but not trigeminal nerve transection eliminated freezing behavior to TMT in rats (Ayers et al., 2013). Thus, innate fear responses to TMT are nevertheless mediated by olfaction, not by nociception. More recently, Fendt et al. (2018) showed that natural predator odor of fox urine elicited $22 \mathrm{kHz}$ alarming calls in Sprague-Dawley rats. However, the researchers failed to observe such ultrasonic vocalizations in response to TMT exposure (Fendt et al., 2018). Moreover, Rampin et al. (2018) found little evidence for the presence of TMT in the fox feces using gas chromatography-mass spectrometry analyses. Taken together, the research data still raises doubts about the potency of TMT to reflect natural predator effect in Norway rat.

\section{Predator odors of mustelids}

Representatives of carnivorous mustelids may also serve as model predators to Norway rats in laboratory and field studies (Apfelbach et al., 2005). Perrot-Sinal et al. (1999) studied the stress-effects of acute (5 min) presentations of 2-propylthietane (main constituent of least weasel Mustela nivalis anal gland secretion) in a relatively small group of Long-Evans hooded rats ( $n=24)$. Both male and female rats responded with reliable increases in corticosterone and ACTH levels though without accompanying changes in locomotor activity measures. Masini et al. (2005) tested potency of several ferret (Mustela putorius $f$. furo) odors to induce HPA axis activation in Sprague-Dawley rats. 30 min of exposure to fur/skin ferret odors resulted in plasma corticosterone and ACTH elevations unlike ferret feces, urine or anal gland secretions and control odors. Behaviorally, rats avoided ferret odors compared to the control as tested in a defensive withdrawal paradigm (Masini et al., 2005). Further studies from the same research group showed that the behavioral responses to ferret odor did not habituate over repeated exposures (1); HPA endocrine responses were still observed after several repeated exposures to predator odor in the home cage (2); previous single exposure to ferret odor increased plasma ACTH and corticosterone response (i.e. sensitization was observed) (3); ferret odor presentation did not produce associative conditioning effects during extinction trials in the defensive withdrawal context (4) (Masini et al., 2006). Independent disruption of neither main olfactory epithelium nor VNO could block ferret odor induced stress responses. Only combined blockade was effective, suggesting that both main and accessory olfactory systems were involved in the processing of ferret odor in male Sprague-Dawley rats (Masini et al., 2010).

\section{Cat predator odors}

The largest body of research comes from the cat (Felis catus) - rat (Rattus norvegicus) model predator-prey studies. Rats exposed to the cat odor show avoidance, retreat and various risk assessment behaviors involved in the monitoring of stimulus, while non-defensive responses like grooming and feeding are inhibited (e.g. Blanchard et al., 1990; Zangrossi \& File, 1992; Dielenberg \& McGregor, 2001). 20 days of repeated exposures of live cat stimulus only slightly decreased defensive responses in Long-Evans hooded rats. Furthermore, the dynamics of organ weights changes enhanced basal plasma corticosterone and reduced corticosterone response to acute stressor suggested that repeated cat exposure is quite comparable to other intense, chronic stressors (Blanchard et al., 1998). Exposure to cat odor leads to prolonged state of anxiety that was registered in the elevated plus maze beyond the period of odor exposure (e.g. Zangrossi \& File, 1992). File et al. (1993) documented a significant plasma corticosterone response to the 5 min presentations of fir/skin cat odor in male Lister hooded rats. However, after 5 consecutive days of exposure, there was no difference in plasma corticosterone concentration between experimental and control groups, suggesting habituation to the predator odor at the hormonal level. Remarkably, one week after only a single 10-min presentation of cat urine, rats exhibited significantly increased levels of avoidance and anxiety-like behavior in the plus-maze test, consistent with the concept of sensitization (Cohen \& Zahar, 2004). Although Dielenberg \& McGregor (2001) concluded that at least 5 laboratory rat strains as well as wild-derived rats are sensitive to cat odor exposure, genetic background of test-subjects may interfere with predator odor effects. Hogg \& File (1994) described two distinct groups of Lister hooded rats- responders and non-responders. Both they were similar in their explorative activity towards neutral odor, but responsive or non-responsive to cat odor. Bowen et al. (2014) while exposing cat fur balls to Wistar rats also identified passive and active responders to the predator odor. Active responders spent more time investigating stimulus and had substantially lower plasma levels of corticosterone than passive responders. Different cat odor sources were compared. For instance, Blanchard et al. (2003) tested cat fir/skin odor, feces and urine under the same behavioral paradigm in male Long-Evans hooded rats. They showed that only cat fir/skin odor and feces but not urine promoted defensive behavior. And only fir/skin odor was potent enough to elicit fear conditioning. So that, fir/skin odor may signal of immediate danger. Similarly, Voznessenskaya et al. (2003) could not find significant differences in plasma corticosterone levels in pregnant female rats exposed to predator compared to non-predator urine. However, plasma corticosterone measurement may not be a method of choice to evaluate predator-induced activation of HPA axis. Thus, Cinque et al. (2018) found that a single 15 min exposure of bedding contaminated by male cat urine resulted in increased levels of fecal corticosterone metabolite in both male and female Wistar rats compared to baseline. Urine from a bobcat (Lynx rufus), another representative of felids, also appeared to be a potent neuroendocrine modulator, as elevated plasma corticosterone was observed in Wistar rats upon its exposure (Whitacker \& Gilpin, 2015).

In addition, strong evidence that cat odor possesses kairomone-like properties in relation to Norway rat was obtained at the neural level. In Wistar rats cat fir/skin odor exposure promoted activation of Fos in the accessory olfactory bulb and its projection areas, anterior olfactory nucleus, medial prefrontal cortex, striatum, and a medial hypothalamic circuit associated with defensive behavior (McGregor et al., 2004; Staples et al., 2008). In contrast, under the same experimental conditions, of olfactory structures, TMT activated only the glomeruli of the main olfactory bulb (Staples et al., 2008).

Another general consideration about predator odor potency to induce stress response under laboratory conditions in Norway rats is the origin of test-subjects, more precisely the degree of their domestication. For instance, Yin et al. (2017) studied the effects of repeated exposures of domestic cat urine in wild-derived Norway rats (F1s) in the withdrawal apparatus. The researchers observed profound stress hormones (ACTH and corticosterone) elevations in blood serum that habituated even more slowly than defensive behavioral responses. These results somewhat stand out from the previous research in laboratory rat strains (e.g. File et al., 1993) and may be partially attributed to the genetic background of rat ancestors and cat, as both were captured from the wild in the same region of China. Similarly, Storsberg et al. (2018) noticed a tendency for a more profound corticosterone response to TMT in a stock of wildderived Norway rats, but not in Lister hooded laboratory strain. Thus, HPA axis of wild-derived rats may be even more affected by predator odors than that of laboratory strains.

Overall, specific domestic cat odors appear to be most potent in eliciting HPA axis activation in Norway rats, as far as they produced the largest spectrum of short-term and long-term responses under controlled laboratory conditions. But it is obvious that odors of predators are partial cues as they can elicit only less intense reactions than live predators. Alternatively, prey reactions may rely not 
only on predator species specificity itself, but also on common carnivorous diet metabolites as it was suggested by e.g. Nolte et al. (1994) or Berton et al. (1998). Ferrero et al. (2011) identified 2-phenylethylamine (PEA) as a urine-derived chemical produced by a wide range of predators and responsible for eliciting prey avoidance behavior upon detection by rodent olfactory receptor TAAR4. Sprague-Dawley rats reliably avoided a corner of open-field arena scented with PEA, as well as developed associated acute increase in plasma corticosterone. Intriguingly, urines of the Felidae species lion (Panthera leo) and serval (Leptailurus serval) were found to be the most enriched in PEA content (Ferrero et al., 2011).

\section{Effects of predator odors on reproduction in rats}

Chronic exposure to the odor of natural predator negatively affects reproduction in a number of prey species, including hamsters, voles, gerbils and mice (see Apfelbach et al., 2005 for review). In a widely accepted view, there exists the "predator induced breeding suppression" hypothesis, which suggests a trade-off between survival and reproduction under high risk of predation. So that nonbreeding individuals are more likely to avoid predators than those in a reproductive state (e.g. Ruxton \& Lima, 1997). Inhibition of reproductive function by acute predator stress may be adaptive, leading to delay in reproduction until the onset of favorable conditions. Meanwhile, chronic stress attributed to predator presence can result in maladaptive reproductive dysfunction.

At the endocrine level, well-documented suppression of reproduction during stress appears to be caused by specific interactions of HPA axis and hypothalamus-pituitary-gonadal (HPG) axis. Possible interaction sites include: 1) a central inhibition of gonadotropin-releasing hormone $(\mathrm{GnRH})$ release by stress hormones ( $\beta$-endorphin, CRF, glucocorticoids); 2 ) a decrease in pituitary responsiveness to GnRH, resulting in decreased luteinizing hormone (LH) secretion; 3) direct gonadal effects of glucocorticoids with subsequent decrease of responsiveness to $\mathrm{LH}$. Thus, glucocorticoids negatively affect the activity of the reproductive axis at all levels, including the hypothalamus, pituitary, gonads and target tissues of sex steroids (Johnson et al., 1992; Wingfield \& Sapolsky, 2003).

\section{Effects in females}

Female reproductive system appears to be more susceptible to the predator odor effects as well as to generalize stress (Apfelbach et al., 2005; Wingfield \& Sapolsky, 2003). Ovarian cyclicity is a very sensitive indicator of the physiological status of the female. Certain parameters (length, regularity, etc.) of ovarian cycles are influenced by external factors and exact values of the parameters could serve as reliable measure. A number of studies indicate chemical signals as potential effectors (regulators) of ovarian cycles in a variety of mammalian species, including humans (Whitten, 1957; McClintock, 1984; Sokolov et al., 1990, 1992; Voznessenskaya et al., 1992; Koskela et al., 1996; Preti et al., 2003; Kvasha et al., 2019; Laktionova et al., 2020, etc.). Predator chemical signals are the most potent to alter estrus cycles. For example, Koskela et al. (1996) found significant extension of the duration of estrous cycles in bank voles (Cletrionomys glareolus) when they were exposed to least weasel (Mustela nivalis) odors. Exposure to urine odor of ferret (Mustela putorius $f$. furo) significantly delayed ovulation in hamsters (Phodopus campbelli) (Apfelbach et al., 2001). Chronic exposure of mice to cat specific chemical signal L-felinine resulted in profound increase of ovulation rate within a fixed time interval, whereas regular intermittent exposure to the compound caused a significant reduction in a number of cycling females relative to the control group. In the latter case, duration of the estrous cycle in ovulating females also was significantly extended. These findings indicate the significance of chemical cues presentation rate (Kvasha et al., 2018; 2019).

Voznessenskaya et al. (1992) studied the effect of mink (Mustela vision) odor on the frequency of estrous cycles in a large cohort of adult Wistar rats $(n=120)$. 3-4 drops of anal sac secretions from male mink were applied on the bedding of group housed females for 24 hours every 16-20 days. Exposure of aged mink odor to rats in metestrus stage of the cycle led to the delay of next estrus for 4-12 days in $65.2 \%$ of animals. Vomeronasal organ removal, but not main olfactory epithelium oblation, reduced significantly the number of animals with extended estrous cycles. The involvement of the accessory olfactory system may be indicative of specific predator odor effects. Meanwhile, non-specific stress effects could not be excluded. For instance, the effect of mink odor was consistent with observations of spontaneous cyclicity in Long-Evans rats previously subjected to maternal deprivation stress. Deprived rats exhibited significantly more of irregular cycles than non-deprived controls (Mourlon et al., 2011). Partially, lengthening of estrous cycles in rats may be attributed to pseudopregnancy which occurs as a result of mechanical stimulation of rat uterine cervix. In rats, adrenalectomy extends the functional life span of the corpora lutea which is related to the duration of pseudopregnancy and luteotropic prolactin surges (Kawaminami et al., 2002). Thus, corticosterone depletion under chronic stress conditions may result in a more frequent occurrence of prolonged estrus cycles in rats.

Notably, prolonged stress, even if applied prior to mating in females, can negatively affect reproductive outcome. For instance, Geraghty et al. (2015) studied the effects of the immobilization stress that was repeated for 18 days in adult female Sprague-Dawley rats and then it was terminated 4 days prior to mating. Although the researchers did not notice any disruption of estrus cycles during stressing, afterwards they observed a profound reproductive dysfunction, with fewer successful copulation events, fewer pregnancies, and increased embryo resorption rate. Though the obtained negative reproductive outcome was linked rather to stress-induced rise in the hypothalamic inhibitory peptide RFRP3 than to the corticosterone level changes (Geraghty et al., 2015).

\section{Effects in males}

Stress can disrupt male reproduction in several ways: 1) inhibition of hormones of HPG axis; 2) impairment of erectile function; 3 ) extinction of normal reproductive behaviors (Wingfield \& Sapolsky, 2003). A number of studies demonstrated changes in male reproductive physiology due to prolonged predator odor exposures. Wang \& Liu (2002) observed lowered frequency of copulation and decreased reproductive organs weights in root voles (Microtus oeconomus) after 18 days of exposure to the odors of the steppe polecat (Mustela eversmanni) under laboratory conditions. Long-term (4 weeks) exposure of two hamster species (Criteculus triton and Mesocricetus auratus) to the anal gland secretions of Siberian weasel (Mustela sibirica) resulted in the increased levels of plasma cortisol (Zhang et al., 2003). Vasilieva et al. (1999) studied a possible influence of cat urine on reproductive development in male Campbell's hamsters (Phodopus campbelli). Long lasting exposure to cat urine caused reduced body and epididymis weights and increased relative adrenal gland weight. These observations corresponded with meiotic abnormalities in spermatocyte preparations.

Malanina \& Voznessenskaya (2014) exposed male laboratory rats to intact cat urine as well as to cat specific urine compound L-felinine $(0.05 \%, 0.2 \mathrm{ml})$ for two weeks. Both treatments significantly suppressed plasma testosterone. The observed effect may be attributed to the direct inhibitory effect of glucocorticoids on testicular Leydig cell function. Leydig cell sensitivity to LH is decreased by glucocorticoids, probably due to glucocorticoid induced reductions in testicular LH receptors (Bambino \& Hsue, 1981). For instance, Charpenet et al. (1981) observed decreased plasma and testicular testosterone in rats subjected to the chronic intermittent 
immobilization stress. The researchers concluded that such stress effect was related to the suppressed Leydig cell sensitivity to gonadotropins.

\section{Effects on reproductive success}

It has been known for a long time that stress during pregnancy, usually referred to as maternal stress, can impair reproductive outcome in Norway rats (e.g. Pollard, 1984; Guo et al., 1993). Götz et al. (2008) showed that even mild stress such as daily social confrontations during pregnancy resulted in reduced litter sizes and total lower body masses in Long-Evans rats.

Under laboratory conditions negative effects of predator odors on reproductive outcome were demonstrated in the house mouse (Mus musculus), the Mongolian gerbil (Meriones unguiculatus) and the golden hamster (Mesocricetus auratus) (e.g. de Catanzaro, 1988; Vasilieva et al., 2001; Voznessenskaya, 2014; Adduci et al., 2019).

The effect of predator odors on the reproductive success of Norway rats was extensively studied in V.V. Voznessenskaya research group. According to the initial observations, naïve rats from an outbred laboratory population responded with reduced litter sizes to domestic cat (Felis catus) urine exposure during pregnancy. To address the specificity of the stressor effect during pregnancy, several stimuli were tested, namely, urine from feral cats, normally hunting for mice and having mice regularly in their diet (1), the same cat urine treated with $\mathrm{HgSO}_{4}$ to remove sulfur compounds and amines (2), urine from cats maintained on the vegetarian diet (3), urine from overcrowded rats kept on a food-restriction schedule, as a source of conspecific signals of high population density (4) (Voznessenskaya et al., 2003). Controls were treated with either tap water or non-predator (guinea pig) urine. Urine of carnivores is reach in sulfur compounds, which comprise products of protein digestion. Previously, Nolte et al. (1994) found that coyote urine collected from animals on vegetarian diet and urine from meat-fed coyotes treated with $\mathrm{HgSO}_{4}$ had lost its initial aversive properties towards several herbivore species. Similarly, Voznessenskaya et al. (2003) concluded that cat diet was important in inhibiting reproductive outcome in rats. Females exposed to intact urine from feral cats normally hunting for mice, had the smallest litter sizes (e.g. $4.8 \pm 0.4$ vs. $8.6 \pm 0.2$ in guinea pig urine control). All other treatments did not differ in their effects on rat reproductive outcome from tap water control, except for the group that received urine from overcrowded rats (litter size $6.7 \pm 1.2$ ). The last finding suggests that urine from conspecifics can also contain reproductive inhibitory cues, possibly similar in its nature to predator odor cues. Some explanation may rise from the results of later research in mice. Brechbühl et al. (2013) identified sulfur-containing alarm pheromone 2sec-butyl-4,5-dihydrothiazole (SBT) in mice, which shares its chemical structure with TMT, a fearful substance isolated from fox feces (Vernet-Maury et al., 1984). SBT is the major mousy odorant and present almost exclusively in male urine; it is not depleted from urine even after repeated headspace or solvent extractions since its majority is tightly bound to the major urinary proteins (MUPs) (Kwak et al., 2016). Interestingly, the results of another recent research indicated that TMT can also negatively affect reproductive outcome in mice (Adduci et al., 2019). Continuing their research on the influence of cat urine on rat pregnancy outcome, Voznessenskaya et al. (2003) aimed to determine a sensitive period for odor effects during gestation. While manipulating length and onset of cat urine treatment, the researchers concluded that sensitive period occurs within the first half of gestation, and that $48 \mathrm{~h}$ exposure to predator urine up to 3 days after mating is sufficient to reduce reproduction. Reduction in litter size under cat urine exposure could be attributed to the reduced implantation and resorption of embryos during the early stage of gestation. Consistent with morphological observations, plasma progesterone levels were decreased in pregnant rats under cat urine exposure. Meanwhile, corticosterone levels were not elevated. One more important outcome is that predator odor as well as overcrowded conspecific urine produced litters biased toward males. In accordance with theory on reproductive value, total reproductive output of males and females in diploid sexually reproducing species is identical, as everyone has one mother and one father. If less individuals of one sex are produced, then their mean reproductive success will be higher than that of the other sex. Under high risk of predation, males may be also "cheaper" to produce for their mothers. Furthermore, dominance hierarchies in mature rats are more abundant in males than in females (e.g. Schweinfurth, 2020). So that non-dominant omega males normally disperse from their natal colony, and thus they could serve a kind of colony sacrifice to predator.

\section{Discussion}

Chemical signals from Felidae family other than domestic cat urine can also affect reproductive outcome in Norway rats. For instance, female rats from outbred laboratory population if kept in close proximity to lynx (Lynx lynx) had higher pre-implantation losses than control groups held at greater distances. Total losses in experimental groups were twice as high as in control groups. The presence of the predator affected pre-implantation losses, though not as much as the effects on post-implantation losses (Naidenko et al., 2004). A putative cat pheromone precursor L-felinine (2-amino-7-hydroxy-5,5-dimethyl-4-thiaheptanoic acid) is excreted in cat urine in a sex and age-dependent manner (Miyazaki et al., 2006). This enhances informational load of the predators scent mark from a point of view of prey species, since L-felinine concentration is higher in urine of dominant healthy males, potentially the most effective hunters. Lfelinine was found in excretions of several close related Felidae species (Hendriks el al, 1995). Notably, this substance reliably inhibited reproductive activity and reproductive outcome in the house mouse (Voznessenskaya, 2014). Exposure of pregnant females during gestation to felinine $(0.05 \%)$ affected sex-ratio in litters in favor of males. At weaning average body weight of pups prenatally exposed to felinine was significantly lower (Malanina \& Voznessenskaya, 2011).

Assessment of reproductive success in rats was also applied to compare the effects of urine odors from sympatric predators: domestic dog (Canis familiaris), ferret (Mustela putorius), domestic cat (Felis catus) (Klyuchnikova et al., 2020). Females exposed to cat urine during pregnancy had significantly smaller litter sizes. Effects of urines from other predators did not differ from control. Fewer female than male pups were observed only in cat urine exposure group. Weight of pups at weaning was significantly lower for prenatally exposed to cat urine and to ferret urine while dog urine exposures did not affect weight of pups. Thus, assessment of reproductive success in rats may be treated as a robust experimental model to evaluate ecologically relevant stress effects of predator odors. However, the impacts of a generalized response to different stressors and various effects of specific stimuli such as chemical signals are not yet defined.

\section{Conclusion}

Here, we performed a systematic review on potency of predator chemical cues to provoke long lasting and chronic stress responses as well as to inhibit reproduction in Norway rat (Rattus norvegicus). Predator odors of red fox (Vulpes vulpes), ferret (Mustela putorius), domestic cat (Felis catus) and some other related species induce a specific release of glucocorticoid corticosterone in Norway rats. Data on chronic activation of the hypothalamus-pituitary-adrenal (HPA) axis in rats under the influence of chemical signals of predators are quite scarce and not systematic. Dissociation between the primary defensive avoidance reaction and the development of a 
neuroendocrine response may occur. However, domestic cat odors appear to be the most potent in eliciting HPA axis activation in Norway rats, as far as they produced the largest spectrum of short-term and long-term behavioral and neuroendocrine responses under controlled laboratory conditions. This fact may indicate that domestic cat - Norway rat relationship relies on closer predator-prey co-evolutionary processes. The biological activity of natural predator odors also depends on their diet, gender and hormonal status, as well as on a specific signal source (urine, feces, etc.). Interactions of HPA axis and HPG (hypothalamus-pituitary-gonadal) axis result in a well-documented suppression of reproduction under psychological stress. Similarly, chronic exposure to domestic cat urine induced disruption of estrous cycles and reduction of litter size in female rats as well as suppressed plasma testosterone in males. Assessment of reproductive success in rats may be considered as a robust experimental model to evaluate ecologically relevant stress effects of predator odors. Application of this approach could promote development of environmentally friendly methods to control rat population density.

\section{Acknowledgements}

The reported study was funded by RFBR and Moscow city Government according to the research project 19-34-70024.

\section{References}

Adduci, L. B., León, V. A., Busch, M., \& Fraschina, J. (2019). Effects of different odours on the reproductive success of Mus musculus as an alternative method of control. Pest Management Science, 75(7), 1887-1893.

Apfelbach, R., Blanchard, C. D., Blanchard, R. J., Hayes, R. A., \& McGregor, I. S. (2005). The effects of predator odors in mammalian prey species: a review of field and laboratory studies. Neuroscience and biobehavioral reviews, 29(8), 1123-1144.

Apfelbach, R., Wiest, H., \& Vasilieva, N. Y. (2001). Ferret (Mustela putorius f. furo) odor affects the estrous cycle in Campbell's hamster females (Phodopus campbelli). Wissenschaftliche Mitteilungen Niederösterreichisches Landesmuseum, 14, 147-152

Ayers, L. W., Asok, A., Heyward, F. D., \& Rosen, J. B. (2013). Freezing to the predator odor 2,4,5 dihydro 2,5 trimethylthiazoline (TMT) is disrupted by olfactory bulb removal but not trigeminal deafferentation. Behavioural brain research, 253, 54-59.

Bale, T. L., \& Vale, W. W. (2004). CRF and CRF receptors: role in stress responsivity and other behaviors. Annual review of pharmacology and toxicology, 44, 525-557.

Bambino, T. H., \& Hsueh, A. J. (1981). Direct inhibitory effect of glucocorticoids upon testicular luteinizing hormone receptor and steroidogenesis in vivo and in vitro. Endocrinology, 108(6), 2142-2148.

Berton, F., Vogel, E., \& Belzung, C. (1998). Modulation of mice anxiety in response to cat odor as a consequence of predators diet. Physiology \& behavior, 65(2), 247-254.

Blanchard, D. C., Markham, C., Yang, M., Hubbard, D., Madarang, E., \& Blanchard, R. J. (2003). Failure to produce conditioning with low-dose trimethylthiazoline or cat feces as unconditioned stimuli. Behavioral neuroscience, 117(2), 360-368.

Blanchard, R. J., Blanchard, D. C., Rodgers, J., \& Weiss, S. M. (1990). The characterization and modelling of antipredator defensive behavior. Neuroscience \& Biobehavioral Reviews, 14(4), 463-472.

Blanchard, R. J., Nikulina, J. N., Sakai, R. R., McKittrick, C., McEwen, B., \& Blanchard, D. C. (1998). Behavioral and endocrine change following chronic predatory stress. Physiology \& Behavior, 63(4), 561-569. https://doi:10.1016/s0031-9384(97)00508-8

Bowen, M. T., Dass, S. A., Booth, J., Suraev, A., Vyas, A., \& McGregor, I. S. (2014). Active coping toward predatory stress is associated with lower corticosterone and progesterone plasma levels and decreased methylation in the medial amygdala vasopressin system. Hormones and behavior, 66(3), 561-566. https://doi.org/10.1016/j.yhbeh.2014.08.004

Brechbühl, J., Moine, F., Klaey, M., Nenniger-Tosato, M., Hurni, N., Sporkert, F., Giroud, C., \& Broillet, M. C. (2013). Mouse alarm pheromone shares structural similarity with predator scents. Proceedings of the National Academy of Sciences of the United States of America, 110(12), 4762-4767. https://doi.org/10.1073/pnas.1214249110

Bruce, H. (1959). An exteroceptive block to pregnancy in the mouse. Nature, 184, 105.

Buckle A. (2013). Anticoagulant resistance in the United Kingdom and a new guideline for the management of resistant infestations of Norway rats (Rattus norvegicus Berk.). Pest management science, 69(3), 334-341.

Charpenet, G., Tache, Y., Forest, M. G., Haour, F., Saez, J. M., Bemier, M., Ducharme, J. R., Collu, R. (1981). Effects of chronic intermittent immobilization stress on rat testicular androgenic function. Endocrinology 109(4), 1254-1258.

Christian, J. J., \& Davis, D. E. (1964). Endocrines, behavior, and population. Science, 146(3651), 1550-1560.

Cinque, C., Zinni, M., Zuena, A. R., Giuli, C., Alemà, S. G., Catalani, A., Casolini, P., \& Cozzolino, R. (2018). Faecal corticosterone metabolite assessment in socially housed male and female Wistar rats. Endocrine connections, 7(2), 250-257.

Cohen, H., \& Zohar, J. (2004). An animal model of posttraumatic stress disorder: the use of cut-off behavioral criteria. Annals of the New York Academy of Sciences, 1032, 167-178.

Day, H. E., Masini, C. V., \& Campeau, S. (2004). The pattern of brain c-fos mRNA induced by a component of fox odor, 2,5-dihydro-2,4,5trimethylthiazoline (TMT), in rats, suggests both systemic and processive stress characteristics. Brain research, 1025(1-2), 139-151.

de Catanzaro D. (1988). Effect of predator exposure upon early pregnancy in mice. Physiology \& behavior, 43(6), 691-696.

Dias Soares, D., Fernandez, F., Aguerre, S., Foury, A., Mormède, P., \& Chaouloff, F. (2003). Fox odour affects corticosterone release but not hippocampal serotonin reuptake and open field behaviour in rats. Brain research, 961(1), 166-170.

Dielenberg, R. A., \& McGregor, I. S. (2001). Defensive behavior in rats towards predatory odors: a review. Neuroscience \& Biobehavioral Reviews, 25(7-8), 597-609.

Fendt, M., Brosch, M., Wernecke, K. E. A., Willadsen, M., \& Wöhr, M. (2018). Predator odour but not TMT induces 22-kHz ultrasonic vocalizations in rats that lead to defensive behaviours in conspecifics upon replay. Scientific Reports, 8(1), 11041.

Fenn, M. G. P., Macdonald, D. W. (1995). Use of middens by red foxes: risk reverses rhythms of rats. Journal of Mammalogy, 76(1), 130-136.

Ferrero, D. M., Lemon, J. K., Fluegge, D., Pashkovski, S. L., Korzan, W. J., Datta, S. R., Spehr, M., Fendt, M., \& Liberles, S. D. (2011). Detection and avoidance of a carnivore odor by prey. Proceedings of the National Academy of Sciences of the United States of America, 108(27), 11235-11240.

File, S. E., Zangrossi, H., Jr, Sanders, F. L., \& Mabbutt, P. S. (1993). Dissociation between behavioral and corticosterone responses on repeated exposures to cat odor. Physiology \& behavior, 54(6), 1109-1111.

Geraghty, A. C., Muroy, S. E., Zhao, S., Bentley, G. E., Kriegsfeld, L. J., \& Kaufer, D. (2015). Knockdown of hypothalamic RFRP3 prevents chronic stress-induced infertility and embryo resorption. eLife, 4, e04316.

Götz, A. A., Wolf, M., \& Stefanski, V. (2008). Psychosocial maternal stress during pregnancy: effects on reproduction for $F_{0}$ and $F_{1}$ generation laboratory rats. Physiology \& behavior, 93(4-5), 1055-1060.

Gross, C. T., \& Canteras, N S., (2012). The many paths to fear. Nature Review Neuroscience, 13, 651-658. 
Guo, A., Nappi, R. E., Criscuolo, M., Ficarra, G., Amram, A., Trentini, G. P., Petraglia, F., \& Genazzani, A. R. (1993). Effect of chronic intermittent stress on rat pregnancy and postnatal development. European journal of obstetrics, gynecology, and reproductive biology, 51(1), 41-45.

Hendriks, W. H., Moughan, P. J., Tarttelin, M. F., \& Woolhouse, A. D. (1995). Felinine: a urinary amino acid of Felidae. Comparative biochemistry and physiology. Part B, Biochemistry \& molecular biology, 112(4), 581-588.

Hogg, S., \& File, S. E. (1994). Responders and nonresponders to cat odor do not differ in other tests of anxiety. Pharmacology, biochemistry, and behavior, 49(1), 219-222.

Homiack, D., O'Cinneide, E., Hajmurad, S., Barrileaux, B., Stanley, M., Kreutz, M. R., \& Schrader, L. A. (2017). Predator odor evokes sexindependent stress responses in male and female wistar rats and reduces phosphorylation of cyclic-adenosine monophosphate response element binding protein in the male, but not the female hippocampus. Hippocampus, 27(9), 1016-1029.

Johnson, E. O., Kamilaris, T. C., Chrousos, G. P., Gold, P. W. (1992). Mechanisms of stress: a dynamic overview of hormonal and behavioral homeostasis. Neurosciences \& Biobehavioral Reviews, 16(2), 115-130.

Kawaminami, M., Yoshida, M., Moriai, Y., Kurusu, S., \& Hashimoto, I. (2002). Adrenal influence on the persistence of pseudopregnancy in rats. Endocrine journal, 49(3), 357-362.

Keller-Wood, M. E., \& Dallman, M. F. (1984). Corticosteroid inhibition of ACTH secretion. Endocrine reviews, 5(1), 1-24.

Klyuchnikova, M., Laktionova, T., \& Voznessenskaya, V. (2020). Effects of odors from natural predators occupying different ecological niches on reproduction of sympatric Norway rats. Chemical senses, 45(2), 157-157.

Koskela, E., Horne, T., Mappes, T., \& Ylonen, H. (1996). Does risk of small mustelid predation affect the oestrous cycle in the bank vole, Cletrionomys glareolus? Animal Behaviour, 51, 1159-1163.

Kvasha, I. G., Laktionova, T. K., \& Voznessenskaya, V. V. (2018). The presentation rate of chemical signals of the domestic cat Felis catus affects the reproductive status of the house mouse. Biology Bulletin, 45(3), 278-283.

Kvasha, I. G., Laktionova, T. K., \& Voznessenskaya, V. V. (2019). Cat chemical cues effects on mouse estrous cycle depend on concentration and presentation mode. Chemical Senses, 44(3), 36.

Kwak, J., Jackson, M., Faranda, A., Osada, K., Tashiro, T., Mori, K., Quan, Y., Voznessenskaya, V.V., \& Preti, G. (2016). On the persistence of mouse urine odour to human observers: a review. Flavour and Fragrance Journal, 31(4), 267-282.

Laktionova, T., Kvasha, I., \& Voznessenskaya, V. (2020). Male axillary secretions affect saliva LH in women depending on the phase of their menstrual cycle. Chemical Senses, 45(2), 163-164.

Lindsey, J. R., Baker, H. J. (2006). Chapter 1 - Historical Foundations. In M. A. Suckow, S. H. Weisbroth, C. L. Franklin (Eds.), American college of laboratory animal medicine, The laboratory rat (second edition) (pp. 1-52). Academic Press.

Malanina, T. V., \& Voznessenskaya, V. V. (2014). Long-term exposure to predator odors affects plasma testosterone in male rats. Chemical Senses, 39(1), 102-103.

Malanina, T., V., \& Voznessenskaya, V. V. (2011). The influence of L-felinine on reproduction in mice and rats. Chemical Senses, $36(1), 32$.

Masini, C. V., Garcia, R. J., Sasse, S. K., Nyhuis, T. J., Day, H. E., \& Campeau, S. (2010). Accessory and main olfactory systems influences on predator odor-induced behavioral and endocrine stress responses in rats. Behavioural brain research, 207(1), 70-77.

Masini, C. V., Sauer, S., \& Campeau, S. (2005). Ferret odor as a processive stress model in rats: neurochemical, behavioral, and endocrine evidence. Behavioral neuroscience, 119(1), 280-292.

Masini, C. V., Sauer, S., White, J., Day, H. E., \& Campeau, S. (2006). Non-associative defensive responses of rats to ferret odor. Physiology \& behavior, 87(1), 72-81.

McClintock M. K. (1984). Estrous synchrony: modulation of ovarian cycle length by female pheromones. Physiology \& behavior, 32(5), 701705.

McEwen, B. S., \& Wingfield, J. C. (2010). What is in a name? Integrating homeostasis, allostasis and stress. Hormones and behavior, 57(2), 105-111.

McGregor, I. S., Hargreaves, G. A., Apfelbach, R., \& Hunt, G. E. (2004). Neural correlates of cat odor-induced anxiety in rats: region-specific effects of the benzodiazepine midazolam. Journal of Neuroscience, 24(17), 4134-4144.

McGregor, I. S., Schrama, L., Ambermoon, P., \& Dielenberg, R. A. (2002). Not all 'predator odours' are equal: cat odour but not 2,4,5 trimethylthiazoline (TMT; fox odour) elicits specific defensive behaviours in rats. Behavioural brain research, 129(1-2), 1-16.

Miyazaki, M., Yamashita, T., Suzuki, Y., Saito, Y., Soeta, S., Taira, H., Suzuki, A. (2006). A major urinary protein of the domestic cat regulates the production of felinine, a putative pheromone precursor. Chemistry \& Biology, 13(10, 1071-1079.

Morrow, B. A., Elsworth, J. D., \& Roth, R. H. (2002). Fear-like biochemical and behavioral responses in rats to the predator odor, TMT, are dependent on the exposure environment. Synapse (New York, N.Y.), 46(1), 11-18.

Mourlon, V., Naudon, L., Giros, B., Crumeyrolle-Arias, M., \& Daugé, V. (2011). Early stress leads to effects on estrous cycle and differential responses to stress. Physiology \& behavior, 102(3-4), 304-310.

Mucignat-Caretta, C., Redaelli, M., \& Caretta, A. (2012). One nose, one brain: contribution of the main and accessory olfactory system to chemosensation. Frontiers in neuroanatomy, 6, 46.

Naidenko, S. V., Clark, L., Voznessenskaya, V. (2004). Reproductive strategy of the Norway rat, Rattus norvegicus (Murinidae), in the presence of predator. Zoologichesky zhurnal, 83(4), 459-463

Nolte, D. L., Mason, J. R., Epple, G., Aronov, E., \& Campbell, D. L. (1994). Why are predator urines aversive to prey? Journal of Chemical Ecology, 20(7), 1505-1516.

Perrot-Sinal, T. S., Ossenkopp, K. P., \& Kavaliers, M. (1999). Brief predator odour exposure activates the HPA axis independent of locomotor changes. Neuroreport, 10(4), 775-780.

Philipeaux, J. M. (1856). Note sur l'exstirpation des capsules surrenales chez les rats albinos (Mus rattus). Comptes rendus hebdomadaires des séances de l'Académie des sciences, 43, 904-906.

Pollard, I. (1984). Effects of stress administered during pregnancy on reproductive capacity and subsequent development of the offspring of rats: prolonged effects on the litters of a second pregnancy. The Journal of endocrinology, 100(3), 301-306.

Preti, G., Wysocki, C. J., Barnhart, K. T., Sondheimer, S. J., \& Leyden, J. J. (2003). Male axillary extracts contain pheromones that affect pulsatile secretion of luteinizing hormone and mood in women recipients. Biology of reproduction, 68(6), 2107-2113.

Rampin, O., Jerôme, N., Saint-Albin, A., Ouali, C., Boué, F., Meunier, N., \& Nielsen, B. L. (2018). Where is the TMT? GC-MS analyses of fox feces and behavioral responses of rats to fear-inducing odors. Chemical senses, 43(2), 105-115.

Rogovin, K. A., Moshkin, M. P. (2007). Autoregulation in mammalian populations and stress: an old theme revisited. Zhurnal Obshchei Biologii, 68(4), 244-267.

Rogovin, K., Randall, J. A., Kolosova, I., \& Moshkin, M. (2003). Social correlates of stress in adult males of the great gerbil, Rhombomys opimus, in years of high and low population densities. Hormones and Behavior, 43(1), 132-139.

Rosen, J. B., Asok, A., \& Chakraborty, T. (2015). The smell of fear: innate threat of 2,5-dihydro-2,4,5-trimethylthiazoline, a single molecule component of a predator odor. Frontiers in neuroscience, 9, 292. 
Rosen, J. B., West, E. A., \& Donley, M. P. (2006). Not all rat strains are equal: differential unconditioned fear responses to the synthetic fox odor 2,4,5-trimethylthiazoline in three outbred rat strains. Behavioral neuroscience, 120(2), $290-297$.

Ruxton, G. D., \& Lima, S. L. (1997). Predator-induced breeding suppression and its consequences for predator-prey population dynamics. Proceedings of the Royal Society B: Biological Sciences, 264(1380), 409-415.

Rylnikov, V. A., Savinetskaya, L. E., Voznesenskaya, V. V. (1992) Adaptation of Norway rats to continuous action of anticoagulant rodenticides in laboratory conditions. Soviet Journal of Ecology 23(1), 46-51.

Sapolsky, R. M., Romero, L. M., \& Munck, A. U. (2000). How do glucocorticoids influence stress responses? Integrating permissive, suppressive, stimulatory, and preparative actions. Endocrine reviews, 21(1), 55-89.

Schweinfurth, M. K. (2020). The social life of Norway rats (Rattus norvegicus). eLife, 9, e54020.

Scorrano, F., Carrasco, J., Pastor-Ciurana, J., Belda, X., Rami-Bastante, A., Bacci, M. L., \& Armario, A. (2015). Validation of the long-term assessment of hypothalamic-pituitary-adrenal activity in rats using hair corticosterone as a biomarker. The FASEB Journal, 29(3), 859-867.

Selye, H. (1946). The general adaptation syndrome and the diseases of adaptation. The Journal of clinical endocrinology and metabolism, 6 , 117-230.

Sokolov, V. E., Chernyshev, M. K., Voznesenskaya, V. V., \& Zinkevich, E. P. (1990). Biorhythmological approach to assessing the effect of signals on the reproductive status of the gray rat Rattus norvegicus. Izvestiya Akademii Nauk Seriya Biologicheskaya, 2, 248-256

Sokolov, V. E., Voznessenskaya, V. V., \& Zinkevich, E. P. (1992). Olfactory cues and ovarian cycles. In R. L Doty, \& D. Müller-Schwarze (Eds.), Chemical Signals in Vertebrates 6 (pp. 267-270). Springer, Boston.

Staples, L. G., McGregor, I. S., Apfelbach, R., \& Hunt, G. E. (2008). Cat odor, but not trimethylthiazoline (fox odor), activates accessory olfactory and defense-related brain regions in rats. Neuroscience, 151(4), 937-947.

Storsberg, S., Stryjek, R., Modlińska, K., Gottswinter, K., D'Hanis, W., Kröber, A., Wernecke, K., Roskoden, T., \& Fendt, M. (2018). Predator odor induced defensive behavior in wild and laboratory rats: a comparative study. Physiology \& behavior, 194, 341-347.

Strand, T. M., \& Lundkvist, $\AA$. (2019). Rat-borne diseases at the horizon. A systematic review on infectious agents carried by rats in Europe 1995-2016. Infection ecology \& epidemiology, 9(1), 1553461.

Uarquin, D. G., Meyer, J. S., Cardenas, F. P., \& Rojas, M. J. (2016). Effect of overcrowding on hair corticosterone concentrations in juvenile male Wistar rats. Journal of the American Association for Laboratory Animal Science: JAALAS, 55(6), 749-755.

Vasilieva, N. Y., Cherepanova, E. V., Safronova, L. D. (1999). Influence of cats' urinary chemosignals on sexual maturation and meiosis in Campbell's hamster males (Phodopus Campbelli). In: R.E. Johnston, D. Müller-Schwarze, \& P. W. Sorensen (Eds.), Advances in Chemical Signals in Vertebrates (pp. 445-455). Springer, Boston, MA.

Vasilieva, N. Y., Parfenova, V., Apfelbach, R. (2001). The effect of predator odour on reproduction success in three rodent species. In: H.-J. Pelz, D. P. Cowan, \& C. J. Feare (Eds.), Advances in Vertebrate Pest Management II (pp.115-122). Filander, Fürth.

Vernet-Maury, E., Le Magnen, J., \& Chanel, J. (1968). Comportement émotif chez le rat; influence de l'odeur d'un prédateur et d'un nonprédateur [Emotional behavior of rats; influence of the odor of a predator and a non-predator]. Comptes rendus hebdomadaires des seances de l'Academie des sciences. Serie D: Sciences naturelles, 267(3), 331-334.

Vernet-Maury, E., Polak, E. H., \& Demael, A. (1984). Structure-activity relationship of stress-inducing odorants in the rat. Journal of Chemical Ecology, 10(7), 1007-1018

Voznessenskaya, V. V. (2014). Influence of cat odor on reproductive behavior and physiology in the house mouse: (Mus musculus). In C. Mucignat-Caretta (Ed.), Neurobiology of Chemical Communication. CRC Press/Taylor \& Francis.

Voznessenskaya, V. V., \& Malanina, T. V. (2015). Development of nontoxic methods of rodent population control as an alternative approach for big cities life chemistry research: biological systems. In R. Joswik, G. E. Zaikov, A. K. Haghi (Eds.), Life Chemistry Research: Biological Systems (pp. 263-272). Apple Academic Press, Oakville, Canada.

Voznessenskaya, V. V., Klyuchnikova, M. A., Wysocki, C. J. (2010). Roles of the main olfactory and vomeronasal systems in the detection of androstenone in inbred strains of mice. Current Zoology, 56(6), 813-818.

Voznessenskaya, V. V., Naidenko, S. V., Clark, L. (2004). Development of nonlethal methods of rodent population control. In G. E. Zaikov (Ed.), Biotechnology and the environment including biogeotechnology (pp. 59-65). Moscow, Russia.

Voznessenskaya, V. V., Naidenko, S. V., Feoktistova, N. Yu., Krivomazov, G. J., Miller, L. A., \& Clark, L. (2003) Predator odours as reproductive inhibitors for Norway rats. In: G. R. Singleton, L. A. Hinds, C. J. Krebs, D. M. Spratt (Eds.). Rats, Mice and People: Rodent Biology and Management. Vol. 96. ACIAR; Monograph (pp. 131-136). Canberra, Australia.

Voznessenskaya, V. V., Wysocki, C. J., \& Zinkevich, E. P. (1992). Regulation of the rat estrous cycle by predator odors: role of the vomeronasal organ. In R. L. Doty, D. Muller-Schwarze (Eds.), Chemical Signals in Vertebrates 6 (pp. 281-284). Springer, Boston, MA.

Wallace, K. J., \& Rosen, J. B. (2000). Predator odor as an unconditioned fear stimulus in rats: elicitation of freezing by trimethylthiazoline, a component of fox feces. Behavioral neuroscience, 114(5), 912-922.

Wang, Z., \& Liu, J. (2002). Effects of steppe polecat (Mustela eversmanni) odor on social behaviour and breeding of root voles (Microtus oeconomus). Acta Zoologica Sinica, 48(1), 20-26

Whishaw, I. Q. (1999). The laboratory rat, the Pied Piper of twentieth century neuroscience. Brain research bulletin, 50(5-6), 411.

Whitaker, A. M., \& Gilpin, N. W. (2015). Blunted hypothalamo-pituitary adrenal axis response to predator odor predicts high stress reactivity. Physiology \& behavior, 147, 16-22.

Whitten, M. (1957). Effect of exteroceptive factors on the oestrous cycle of mice, Nature, 180, 1436.

Wingfield, J. C., \& Sapolsky, R. M. (2003). Reproduction and resistance to stress: when and how. Journal of neuroendocrinology, 15(8), 711724.

Yin, B., Gu, C., Lu, Y., Hegab, I. M., Yang, S., Wang, A., \& Wei, W. (2017). Repeated exposure to cat urine induces complex behavioral, hormonal, and c-fos mRNA responses in Norway rats (Rattus norvegicus). Die Naturwissenschaften, 104(7-8), 64.

Zangrossi, H., Jr, \& File, S. E. (1992). Behavioral consequences in animal tests of anxiety and exploration of exposure to cat odor. Brain research bulletin, 29(3-4), 381-388.

Zhang, J. X., Cao, C., Gao, H., Yang, Z. S., Sun, L., Zhang, Z. B., \& Wang, Z. W. (2003). Effects of weasel odor on behavior and physiology of two hamster species. Physiology \& behavior, 79(4-5), 549-552.

\section{Citation:}

Klyuchnikova, M.A., Struchkov, P.V., Kvasha, I.G. (2020). The effects of predator odors on stress response and reproduction in Norway rats: a review.

Ukrainian Journal of Ecology, 10(4), 48-55. 